\title{
Erratum: "ICRF Heating Experiment on LHD in Foreseeing a Future Fusion Device" [Plasma Fusion Res. 10, 3405046 (2015)]
}

Tetsuo SEKI, Takashi MUTOH, Kenji SAITO, Hiroshi KASAHARA, Ryosuke SEKI, Shuji KAMIO, Goro NOMURA, Yanping ZHAO ${ }^{1)}$, Sonjong $\mathrm{WANG}^{2)}$ and $\mathrm{LHD}_{\text {Experiment Group }}$ National Institute for Fusion Science, 322-6 Oroshi-cho, Toki 509-5292, Japan

${ }^{1)}$ Institute of Plasma Physics, Chinese Academy of Science, Hefei, Anhui, 230031, P.R. China

${ }^{2)}$ Korea Atomic Energy Research Institute, Daejeon 305-600, Korea Rep.

(Received 10 January 2018 / Accepted 12 January 2018)

(c) 2018 The Japan Society of Plasma Science and Nuclear Fusion Research

DOI: $10.1585 /$ pfr. 13.1905010

In the above article, Ref. [8] was not quoted appropriately. It should be replaced by:

[8] K. Saito et al., Fusion Eng. Des. 96-97, 583 (2015). 